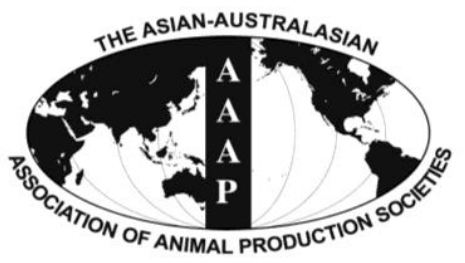

Asian-Aust. J. Anim. Sci.

Vol. 25, No. $10: 1445-1450$

October 2012

www.ajas.info

http://dx.doi.org/10.5713/ajas.2012.12190

\title{
Effects of Alfalfa Meal on Growth Performance and Gastrointestinal Tract Development of Growing Ducks
}

\author{
J. F. Jiang, X. M. Song, X. Huang, W. D. Zhou, J. L. Wu, Z. G. Zhu ${ }^{1}$, H. C. Zheng and Y. Q. Jiang* \\ Institute of Animal Husbandry and Veterinary Science, \\ Zhejiang Academy of Agricultural Sciences, Hangzhou, 310021, China
}

\begin{abstract}
A study was conducted to evaluate effects of alfalfa meal on growth performance and gastrointestinal tract development of growing layer ducks to provide evidence for application of alfalfa meal in the duck industry. Two hundred and fifty-six healthy Shaoxing 7-wk old growing layer ducks were selected and randomly allocated to 1 of 4 dietary treatments based on corn and soybean meal and containing 0,3,6, and $9 \%$ of alfalfa meal for 8 wks. Each treatment consisted of 4 replicates of 16 ducks each. Briefly, birds were raised in separate compartments, and each compartment consisted of three parts: indoor floor house, adjacent open area and a connecting water area. The results showed: i) Growing ducks fed alfalfa meal diet were not significantly different in average daily gain, feed intake and gain-to-feed ratio from those fed no alfalfa diet ( $\mathrm{p}>0.05)$. ii) Alfalfa meal increased the ratio crop, gizzard to live weight, caecum to live weight, the caecum index of growing ducks $(\mathrm{p}<0.05)$. iii) Villus height in duodenum and jejunum of growing ducks increased significantly with the increase of alfalfa meal levels $(p<0.05)$. Crypt depth in duodenum and jejunum of growing ducks decreased significantly with the increase of alfalfa meal levels $(\mathrm{p}<0.05)$. This experiment showed that feeding of alfalfa meal to growing layer ducks could improve gastrointestinal tract growth and small intestinal morphology without effect on performance. This experiment provides evidence that alfalfa meal is a very valuable feedstuff for growing layer ducks. (Key Words: Alfalfa Meal, Growing Ducks, Growth Performance, Gastrointestinal Tract Development)
\end{abstract}

\section{INTRODUCTION}

Alfalfa meal is one of the best sources for protein, and it is a rich source of minerals as well as vitamins (Ensminger, 1992). Specifically, alfalfa contains vitamins A, D, E, K, C, B1, B2, B6, B12, Niacin, Panthothanic acid, Inocitole, Biotin, and Folic acid. Alfalfa also contains the following minerals: Phosphorus, Calcium, Potassium, Sodium, Chlorine, Sulfur, Magnesium, Copper, Manganese, Iron, Cobalt, Boron, and Molybdenum. Alfalfa is well balanced in amino acids and rich in carotenoids, and xanthophylls that give poultry carcasses their desirable yellow color (Sen et al., 1998; Ponte et al., 2004). Alfalfa also contains high levels (2 to $3 \%$ of DM) of saponins, which have been shown to have hypocholesterolemic, anticarcinogenic, antiinflammatory, and antioxidant properties (Klita et al., 1996; Ponte et al., 2004). Alfalfa is a commercially

\footnotetext{
* Corresponding Author: Y. Q. Jiang. Tel: +86-0571-86400465, Fax: +86-0571-86400836, E-mail: jyq61@ @ohu.com

${ }^{1}$ National Shaoxing Duck Breeding Farm, Shaoxing, 312000, Zhejiang, China.

Submitted Apr. 11, 2012; Accepted May 30, 2012; Revised Jul. 2, 2012
}

available feedstuff that is high in protein $(17.5 \%)$ and crude fiber $(24.1 \%)$ while exhibiting a relatively low metabolizable energy $(1,200 \mathrm{kcal} / \mathrm{kg})$ (National Research Council, 1994). Alfalfa, with high fiber content, has been shown to slow the passage rates in the avian gastrointestinal tract (Sibbald, 1979). This is very advantageous, since indigenous microorganisms in the gastrointestinal tracts of poultry can ferment dietary fiber sources to some extent (Ricke et al., 1982) and a slow passage rate would further breakdown of feed and extend microbial fermentation.

There are many researches on application of alfalfa meal as a feed supplement in laying hens and broilers, previous studies have shown that effects of alfalfa meal on performance in broilers, geese, turkeys and quails is variable. Lepkovsky et al. (1950) suggested that an addition of more than 5\% alfalfa meal adversely affected performance in broilers. Heywang (1950) reported adding 5, $10,15,20 \%$ alfalfa meal to diets had no effect on feed consumption, but adding more than $5 \%$ alfalfa meal decreased egg production. Potter and Shelton (1973) reported diet with $5 \%$ alfalfa meal did not affect the average body weight gain but increased food consumption and 
decreased the efficiency of food utilization in turkeys. Diets containing $10 \%$ or more alfalfa meal affected feed consumption in geese, turkeys, quails and broilers (Cheeke et al., 1983) and daily weight gain and feed efficiency in geese (Yu et al., 1998). Adding 3, 6 and 9\% alfalfa meal to diets of laying quails had no significant effect on live weight, egg production, feed consumption or feed efficiency (Güçlu et al., 2004).

The influence of alfalfa meal in ducks is not clear. Duck is a waterfowl and has a different physiology than other poultry (Ali et al., 2008). Ducks intake much fodder succulence in practice, which showing ducks should be able to utilize alfalfa. To the authors' knowledge, so far, insufficient or no investigations at all have been carried out into the effects of the alfalfa meal upon duck. Therefore in the present experiment, effects of alfalfa meal added to the diet of ducks on performance and gastrointestinal tract development were investigated.

\section{MATERIALS AND METHODS}

\section{Experimental animals and diets}

Shaoxing duck is a local breed in China, characterized by small body size, early maturity and high egg production. In the present experiment, 256 Shaoxing 7-w-old growing ducks for egg production from National Shaoxing Duck Breeding Farm (Zhejiang, China) were selected and randomly allocated to the control and alfalfa-treated groups, with alfalfa supplemented to the basal diet at the level of 3 , 6 and $9 \%$, respectively, for a period of 8 wks. Each treatment consisted of 4 replicates of 16 ducks each. The place for raising ducks was comparted into 16 compartments. Each replicate was individually arranged in one compartment and each compartment has three parts: indoor floor pens, adjacent open sports ground and a connecting water area for ducks to paddle in. The dimensions of each indoor floor pens were $9 \mathrm{~m} \times 2 \mathrm{~m} \times 1.5 \mathrm{~m}$, the dimensions of each adjacent open field were $10 \mathrm{~m} \times 2 \mathrm{~m}$ $\times 1.5 \mathrm{~m}$, and the dimensions of water area were $10 \mathrm{~m} \times 2 \mathrm{~m}$ $\times 1.5 \mathrm{~m}$. The whole indoor house including all indoor floor pens has enclosing wall at $2.5 \mathrm{~m}$ and sloping roof at height $2.5 \mathrm{~m}$. Alfalfa was harvested at the start of flowering, dried in the sun by $5 \mathrm{~h}$, passed through a hot air drier at $500^{\circ} \mathrm{C}$ by $3 \mathrm{~min}$ and graded by mesh size ( $1 \mathrm{~mm}$ to $2 \mathrm{~mm}$ ). Alfalfa meal composition: CP 14.2, EE 2.6, CF 21, ASH 8.3, Ca 1.52, $\mathrm{P} 0.22$. CP, EE, CF, ASH, Ca and $\mathrm{P}$ were respectively analyzed by kjeldahl nitrogen determination method, soxhlet extraction method, acid-alkali method, ashing method, EDTA complexometric titration method, molybdate yellow spectrophotometric method.

Ducks were maintained on the growing diet ad libitum. The main characteristics and composition of diets are shown in Table 1 following the feeding and housing standards of the breed. The breeders' diet for 5- to 17-wkold formulate containing $10.8 \mathrm{MJ} / \mathrm{kg}$ energy, $16.0 \%$ crude protein, $0.9 \%$ calcium, $0.5 \%$ phosphorus, $0.3 \%$ methionine

Table 1. Composition and nutrient level of diets

\begin{tabular}{|c|c|c|c|c|}
\hline Ingredients (\%) & Treatment1 & Treatment 2 & Treatment 3 & Treatment 4 \\
\hline Corn & 54.5 & 56.4 & 56.5 & 57.8 \\
\hline Soybean meal & 20 & 20.3 & 20.2 & 20.4 \\
\hline Alfalfa meal & 0 & 3 & 6 & 9 \\
\hline Wheat middlings & 21.7 & 16.5 & 13.5 & 9 \\
\hline Methionine & 0.1 & 0.1 & 0.1 & 0.1 \\
\hline Stone meal & 2 & 2 & 2 & 2 \\
\hline Calcium hydrogen phosphate & 0.4 & 0.4 & 0.4 & 0.4 \\
\hline Salt & 0.3 & 0.3 & 0.3 & 0.3 \\
\hline Mineral and vitamin premix ${ }^{1}$ & 1 & 1 & 1 & 1 \\
\hline Total & 100 & 100 & 100 & 100 \\
\hline \multicolumn{5}{|l|}{ Nutrient content ${ }^{2}$} \\
\hline Metabolizable energy (MJ/kg) & 10.80 & 10.81 & 10.80 & 10.80 \\
\hline Crude protein $(\%)$ & 16.01 & 16.02 & 16.03 & 16.01 \\
\hline Crude fibre $(\%)$ & 2.49 & 3.03 & 3.57 & 4.10 \\
\hline Calcium (\%) & 0.91 & 0.90 & 0.90 & 0.91 \\
\hline Phosphorus (\%) & 0.50 & 0.51 & 0.52 & 0.51 \\
\hline Methionine (\%) & 0.30 & 0.30 & 0.30 & 0.30 \\
\hline Lysine (\%) & 0.79 & 0.79 & 0.79 & 0.79 \\
\hline
\end{tabular}

${ }^{1}$ Premix provided, for each kg of complete diet, Vitamin A, 3,000 IU; Vitamin $\mathrm{D}_{3}$, $600 \mathrm{IU}$; Vitamin E, $8.0 \mathrm{mg}$; Vitamin K, $2.0 \mathrm{mg}$; Vitamin $\mathrm{B}_{1}, 3.0 \mathrm{mg}$; Vitamin $\mathrm{B}_{2}, 5.0 \mathrm{mg}$; Vitamin $\mathrm{B}_{12}, 0.02 \mathrm{mg}$; folic acid, $1.0 \mathrm{mg}$; niacin, $60 \mathrm{mg}$; pantothenic acid, $11 \mathrm{mg}$; Mn, $30 \mathrm{mg}$; Zn, $60 \mathrm{mg} ; \mathrm{Fe}, 96 \mathrm{mg} ; \mathrm{Cu}, 8.0 \mathrm{mg}$; $0.45 \mathrm{mg} ; \mathrm{Se}, 0.15 \mathrm{mg}$.

${ }^{2} \mathrm{ME}$ based on calculated values, others were analyzed value. 
and $0.7 \%$ lysine. The place for raising ducks consists of three parts: indoor floor house, adjacent open sports ground and a connecting water area. Birds were raised in separate compartments with 8 male and 8 female ducks each. Ducks were given free access to water and food with plastic drinkers and plastic feeders under natural $13 \mathrm{~h}$ lighting and low lighting throughout the night (the illumination intensity was $5 \mathrm{Lx}$ in the house). The trial was conducted in 2010 , and environmental temperature during trial was 19 to $29^{\circ} \mathrm{C}$. All procedures of this experiment were approved by the Animal Care and Use Committee of Zhejiang Province, China.

\section{Parameters measured}

Growth performances were determined from 7 to 15 wks old, feed consumption was recorded daily. Weight gain, feed intake and feed/gain of ducks were measured.

At 15-wk old, ducks were weighed after a period of fasting $(12 \mathrm{~h})$ with free access to water and then 2 male and 2 female ducks selected randomly from each group were slaughtered by neck cut for tissue sampling. The gastrointestinal tract was quickly removed from the body.

\section{Measurement of gastrointestinal tract indices}

The crop and gizzard tissues were cleaned and weighed. Cecal contents were immediately removed and the cecal wall was flushed clean with $0.9 \%$ saline, blotted dry on filter paper, and weighed, the same procedure was applied to the small intestine. The length of the small intestine and caecum was measured to the nearest $1 \mathrm{~mm}$ under the same conditions.

The ratio crop, gizzard to live weight was expressed as percentages of weights of the tissues to live body weight. Small intestine index and caecum index were expressed as the value of small intestine and caecum lengths and to live body weight $(\mathrm{mm} / \mathrm{g}$ of $\mathrm{BW})$.

\section{Measurement of small intestinal mucosa morphology}

Samples of duodenum, jejunum and ileum were fixed immediately in formalin for the measurement of villus height and crypt depth after ducks were slaughtered. Samples were fixed in $10 \%$ formalin, dehydrated by immersion in a graded series of alcohols of increasing concentration (from $70 \%$ to absolute), infiltrated with xylene, and embedded in paraffin. A microtome was used to make $5-\mu \mathrm{m}$ cuts that were mounted in glass slides and stained with hematoxylin and eosin. Villus height $(\mu \mathrm{m})$ and crypt depth $(\mu \mathrm{m})$ from each slice were measured in approximately 50 microscopic fields by using an image analysis system. (Image-Pro, Media Cybernetics, Inc., Silver Springs, MD). The villus height was measured from the tip of the villi to the villus crypt junction, and the crypt depth was measured from the villus crypt junction to the base of the crypt.

\section{Statistical analysis}

All data were arranged to evaluate by analysis of variance following the mixed procedure in a completely randomized design using the SAS software program (SAS, 1998), the statistical model included the main and interactive effects of alfalfa meal and sex. Treatment differences were considered significant at $\mathrm{p} \leq 0.05$.

\section{RESULTS AND DISCUSSION}

\section{Effect of alfalfa meal on growth performance of growing ducks}

All ducks fed alfalfa meal diet were not significantly different in body weight, average daily gain, mortality, feed intake and gain-to-feed ratio from those on the control (p>0.05) (Table 2). The results showed 3 to $9 \%$ alfalfa meal in diet didn't affect the growth of growing ducks.

Previous studies have shown that effects of alfalfa meal on performance in animals may vary. Heywang (1950) reported adding 5, 10, 15, 20\% alfalfa meal to diets had no effect on feed consumption, but adding more than 5\% alfalfa meal decreased egg production. Lepkovsky et al. (1950) suggested that an addition of more than $5 \%$ alfalfa meal adversely affected performance in broilers. Potter and Shelton (1973) reported diet with 5\% alfalfa meal did not affect the average body weight gain but increased food consumption and decreased the efficiency of food utilization in turkeys aged between 4 and 8 wks. Diets containing $10 \%$ or more alfalfa meal affected feed consumption in geese, turkeys, quails and broilers (Cheeke et al., 1983) and daily weight gain and feed efficiency in

Table 2. Effects of alfalfa meal on growth performance of growing ducks from 7 to 15 wks old

\begin{tabular}{|c|c|c|c|c|c|c|}
\hline \multirow{2}{*}{ Items } & \multicolumn{4}{|c|}{$\%$ Alfalfa meal in diet } & \multirow{2}{*}{ SEM $^{1}$} & \multirow{2}{*}{$\mathrm{p}$ values } \\
\hline & 0 & 3 & 6 & 9 & & \\
\hline Final body weight (kg) & 1.493 & 1.525 & 1.533 & 1.529 & 0.02 & 0.1653 \\
\hline Mortality (\%) & 4.0 & 3.75 & 3.25 & 3.5 & 0.7 & 0.8381 \\
\hline Average daily gain (g) & 10.05 & 10.95 & 11.05 & 10.45 & 0.18 & 0.2164 \\
\hline Feed intake (g/bird per $\mathrm{d})$ & 126.0 & 127.1 & 129.8 & 126.5 & 1.90 & 0.1964 \\
\hline Feed:gain ratio & 12.54 & 11.60 & 10.77 & 12.10 & 0.97 & 0.2758 \\
\hline
\end{tabular}

${ }^{1}$ Standard error of means. Groups did not differ significantly $(\mathrm{p}>0.05)$. 
Table 3. Effects of alfalfa meal on gastrointestinal tract growth of growing ducks at 15 wks old

\begin{tabular}{|c|c|c|c|c|c|c|c|c|}
\hline \multirow{2}{*}{ Items } & \multicolumn{4}{|c|}{$\%$ Alfalfa meal in diet } & \multirow{2}{*}{$\mathrm{SEM}^{1}$} & \multicolumn{3}{|c|}{$\mathrm{p}$ values } \\
\hline & 0 & 3 & 6 & 9 & & Alfalfa meal & Sex & Alfalfa meal $\times$ sex \\
\hline Gizzard to live weight ratio (\%) & $3.47^{\mathrm{b}}$ & $3.50^{\mathrm{b}}$ & $3.53^{\mathrm{b}}$ & $3.94^{\mathrm{a}}$ & 0.09 & 0.0149 & 0.1166 & 0.6917 \\
\hline Crop to live weight ratio $(\%)$ & $0.34^{\mathrm{b}}$ & $0.41^{\mathrm{a}}$ & $0.45^{\mathrm{a}}$ & $0.48^{\mathrm{a}}$ & 0.02 & 0.0048 & 0.2779 & 0.6051 \\
\hline Small intestine to live weight ratio (\%) & 3.10 & 3.23 & 3.27 & 3.33 & 0.17 & 0.8168 & 0.0055 & 0.8568 \\
\hline Caecum to live weight ratio (\%) & $0.293^{\mathrm{b}}$ & $0.295^{\mathrm{b}}$ & $0.332^{\mathrm{a}}$ & $0.320^{\mathrm{a}}$ & 0.004 & 0.0440 & 0.6149 & 0.7249 \\
\hline Small intestine index $(\mathrm{mm} / \mathrm{g})$ & 1.07 & 1.07 & 1.08 & 1.13 & 0.04 & 0.5822 & 0.0485 & 0.3617 \\
\hline Caecum index $(\mathrm{mm} / \mathrm{g})$ & $0.101^{\mathrm{c}}$ & $0.108^{\mathrm{b}}$ & $0.112^{\mathrm{a}}$ & $0.113^{\mathrm{a}}$ & 0.002 & 0.0319 & 0.1831 & 0.5197 \\
\hline
\end{tabular}

$\overline{a, b, c}$ Means within a row with no common superscript differ statistically $(\mathrm{p}<0.05) .{ }^{1}$ Standard error of means.

geese (Yu et al., 1998). Adding 3, 6 and 9\% alfalfa meal to diets of laying quails had no significant effect on live weight, egg production, feed consumption or feed efficiency (Güçlu et al., 2004). The variability in performance may be due to there was difference in the ability in utilization the alfalfa meal among poultry species, because there was difference in physiology among poultry species.

\section{Effect of alfalfa meal on gastrointestinal tract growth of growing ducks}

The effects of alfalfa meal on gastrointestinal tract development of growing ducks are shown in Table 3. Alfalfa meal increased significantly the ratio crop, gizzard to live weight, caecum to live weight, and the caecum index of ducks $(\mathrm{p}<0.05)$. The effect of alfalfa meal on the ratio small intestine to live weight and small intestine index of growing ducks were not significant $(p>0.05)$. Sex had significant effect on the ratio small intestine to live weight and small intestine index of growing ducks $(\mathrm{p}<0.05)$, and had no significant effects on the ratio crop, gizzard to live weight, caecum to live weight, and the caecum index of growing ducks ( $p>0.05$ ) (Table 3 ).

Alfalfa meal increased significantly the ratio crop, gizzard to live weight, caecum to live weight, and the caecum index of ducks, which showed alfalfa meal enhanced gastrointestinal tract development of ducks. Alfalfa is a commercially available feedstuff that is high in crude fiber (24.1\%) (National Research Council, 1994). The increase of the fiber content in a diet benefits the digestive system by normalizing colonic function and by increasing fecal weights and evacuation frequency (Salvin et al., 1985) Birds can digest fibre through fermentation, mainly in the caecum (Clench and Mathis, 1995). Their capabilities of fibre digestion depend on individual differences, age of birds and feed composition. It has been shown that alfalfa, with high crude fiber, has a very long transit time in the gastrointestinal tract of chickens. The increase in transit time favors bacteria degrading dietary fiber into fermentable substrates. These actions increased mucosal structure and function as well as increased the populations of commensal bacteria in the gastrointestinal tract, which would help maintain the small and large intestine (Buddington et al., 1999; McReynolds et al., 2009).

\section{Effect of alfalfa meal on small intestinal morphology of growing ducks}

The effects of alfalfa meal on the small intestinal morphology in growing ducks are shown in Table 4. The effects of alfalfa meal on villus height in duodenum and jejunum were significant, villus height in duodenum and jejunum increased with the increase of alfalfa meal levels $(p<0.05)$. Villus height were similar in ileum among all groups $(p>0.05)$. The effects of alfalfa meal on crypt depth in duodenum and jejunum were significant, crypt depth in duodenum and jejunum decreased with the increase of alfalfa meal levels $(p<0.05)$. Crypt depth were similar in ileum among all groups $(\mathrm{p}>0.05)$. Sex had no significant effects on villus height and crypt depth in duodenum, jejunum and ileum ( $>>0.05)$ (Table 4).

Table 4. Effects of alfalfa meal on small intestinal morphology of growing ducks at 15 wks old

\begin{tabular}{|c|c|c|c|c|c|c|c|c|c|}
\hline \multirow{2}{*}{ Items } & & \multicolumn{4}{|c|}{$\%$ Alfalfa meal } & \multirow{2}{*}{$\mathrm{SEM}^{1}$} & \multicolumn{3}{|c|}{$\mathrm{p}$ values } \\
\hline & & 0 & 3 & 6 & 9 & & Alfalfa meal & Sex & Alfalfa meal $\times$ sex \\
\hline \multirow[t]{2}{*}{ Duodenum } & Villus height $(\mu \mathrm{m})$ & $886.91^{c}$ & $1,006.66^{\mathrm{b}}$ & $1,111.49^{\mathrm{a}}$ & $1,170.52^{\mathrm{a}}$ & 14.59 & 0.0006 & 0.2661 & 0.1486 \\
\hline & Crypt depth $(\mu \mathrm{m})$ & $113.18^{\mathrm{a}}$ & $108.25^{\mathrm{b}}$ & $106.87^{\mathrm{b}}$ & $105.62^{b}$ & 0.62 & 0.0107 & 0.1014 & 0.2548 \\
\hline \multirow[t]{2}{*}{ Jejunum } & Villus height $(\mu \mathrm{m})$ & $847.07^{\mathrm{b}}$ & $944.66^{\mathrm{a}}$ & $959.40^{\mathrm{a}}$ & $960.55^{\mathrm{a}}$ & 5.80 & 0.0003 & 0.6389 & 0.5142 \\
\hline & Crypt depth $(\mu \mathrm{m})$ & $122.74^{\mathrm{a}}$ & $120.50^{\mathrm{a}}$ & $117.71^{\mathrm{ab}}$ & $114.07^{\mathrm{b}}$ & 0.75 & 0.0208 & 0.6125 & 0.7834 \\
\hline \multirow[t]{2}{*}{ Ileum } & Villus height $(\mu \mathrm{m})$ & 643.09 & 644.17 & 645.53 & 647.70 & 0.87 & 0.4136 & 0.3043 & 0.7612 \\
\hline & Crypt depth $(\mu \mathrm{m})$ & 145.18 & 142.59 & 144.22 & 143.71 & 0.48 & 0.5961 & 0.8926 & 0.8852 \\
\hline
\end{tabular}

$\overline{\mathrm{a}, \mathrm{b}, \mathrm{c}}$ Means within a row with no common superscript differ statistically $(\mathrm{p}<0.05) .{ }^{1}$ Standard error of means. 
The morphology of the intestinal epithelium is particularly affected by the diet. Chickens fed wet diets had increased villus height and less depth of crypts in duodenum, jejunum, ileum, ceca and colon compared to broiler chickens given dry diets (Yasar et al., 1999). Chicks fed with $B$. subtilis had increased villus height of duodenum and ileum in 28 d old (Samanya et al., 2002). Villus height was greater in birds fed yeast cell wall than in the control birds, no significant differences were found in crypt depth in small intestinal (Zhang et al., 2005). The addition of synbiotic increased the villus height and decreased the crypt depth in ileum in broiler chickens (Awad et al., 2008). Dietary supplementation of mannan-oligosaccharides and direct feed microbials led to an increase in villus height and width, as well as a decrease in crypt depth in all parts of the intestine in broiler (Markovicva et al., 2009). The addition of prebiotic or antibiotic increased the villus height in duodenum, and prebiotic increased villus width of duodenum and ileum compared with antibiotic and control group. However antibiotic increased duodenal crypt depth compared with the prebiotic and control group in broiler chickens (Sayrafi et al., 2011). The supplementation with organic acids significantly increased the villus height in the duodenum, jejunum, the crypt depth in the duodenum, jejunum, and ileum was not affected in broiler chickens (Adil et al., 2010).

The intestinal villus and crypt morphology has been associated with intestine function and growth in animals. According to Tivey and Smith (1989), changes in enterocytes development and villi structure determine the digestive and absorptive capacity of the small intestine. Histological examination reveals the crypts to be the place of epithelial regeneration (Paulus et al., 1992). A lengthening of the villi increases the surface area for nutrient absorption. The crypt can be considered as the villus factory, and a large crypt indicates fast tissue turnover and high demand for new tissue (Yason et al., 1987).

It can be concluded that alfalfa meal in diet has the potential to improve gastrointestinal tract growth and the intestinal morphology of growing ducks for egg production. The search indicates alfalfa meal is very available feedstuff on growing egg-type duck industry. Application of alfalfa meal as a feed supplement in growing egg-type ducks not only will benefit gastrointestinal development of growing ducks, but also will economize traditional ingredients which are becoming costly or less available.

\section{ACKNOWLEDGEMENTS}

This work was supported by Grant 2010R50027 from Zhejiang province key science and technology innovation team program, Science Technology Department of Zhejiang Province, China.

\section{REFERENCES}

Adil, S., T. Banday, G. A. Bhat, M. S. Mir and M. Rehman. 2010. Effect of dietary supplementation of organic acids on performance, intestinal histomorphology, and serum biochemistry of broiler chicken. Vet. Med. Int. 2010:479-485.

Ali, M. S., H. S. Yang, J. Y. Jeong, S. H. Moon, Y. H. Hwang, G. B. Park and S. T. Joo. 2008. Effect of chilling temperature of carcass on breast meat quality of duck. Poult. Sci. 87:18601867.

Awad, W., K. Ghareeb and J. Böhm. 2008. Intestinal structure and function of broiler chickens on diets supplemented with a synbiotic containing Enterococcus faecium and oligosaccharides. Int. J. Mol. Sci. 9:2205-2216.

Buddington, R. K., K. K. Buddington and G. D. Sunvold. 1999. Influence of fermentable fiber on small intestinal dimensions and transport of glucose and proline in dogs. Am. J. Vet. Res. 60:354-358.

Cheeke, P. R., J. S. Powley, H. S. Nakaue and G. H. Arscott. 1983. Feed preference responses of several avian species fed alfalfa meal, high-and low-saponin alfalfa, and quinine sulfate. Can. J. Anim. Sci. 63:707-710.

Clench, M. H. and J. R. Mathis. 1995. The avian cecum: a review. Wilson. Bull. 107:93-121.

Ensminger, M. E. 1992. Poultry science: Feeds and additives. 3th Ed, Interstate Publishers, Inc., Danville, Illinois, USA.

Güçlu, B. K., K. M. Işcan, F. U. yanik, M. Eren and A. C. Ağca. 2004. Effect of alfalfa meal in diets of laying quails on performance, egg quality and some serum parameters. Arch. Anim. Nutr. 58:255-263.

Heywang, B. W. 1950. High levels of alfalfa meal in diets for chickens. Poult. Sci. 29:804-811.

Klita, P. T., G. W. Mathison, T. W. Fenton and R. T. Hardin. 1996. Effects of alfalfa root saponins on digestive function in sheep. J. Anim. Sci. 74:1144-1156.

Lepkovsky, S., W. Shaeleff, D. Peterson and R. Perry. 1950. Alfalfa inhibitor in chick rations. Poult. Sci. 29:208-213.

Markovicva, R., D. Šefera, M. Krsticvb and B. Petrujkicv. 2009. Effect of different growth promoters on broiler performance and gut morphology. Arch. Med. Vet. 41:163-169.

McReynolds, J. L., K. J. Genovese, H. He, C. L. Swaggerty, J. A. Byrd, S. C. Ricke, D. J. Nisbet and M. H. Kogut. 2009. Alfalfa as a nutritive modulator in maintaining the innate immune response during the molting process. J. Appl. Poult. Res. 18:410-417.

National Research Council. 1994. Nutrient Requirements of Poultry, Ninth Revised ed. National Academy Press, Washington, DC, USA.

Paulus, U., C. S. Potten and M. Loeffler. 1992. A model of the control of cellular regeneration in the intestinal crypt after perturbation based solely on local stem cell regulation. Cell Prolif. 25:559-578.

Ponte, P. I., I. Mendes, M. Quaresma, M. N. Aguiar, J. P. Lemos, L. M. Ferreira, M. A. Soares, C. M. Alfaia, J. A. Prates and C. M. Fontes. 2004. Cholesterol levels and sensory characteristics of meat from broilers consuming moderate to high levels of alfalfa. Poult. Sci. 83:810-814.

Potter, L. M. and J. R. Shelton. 1973. Evaluation of alfalfa meal as a dietary ingredient for young turkeys. Br. Poult. Sci. 14:251256. 
Ricke, S. C., P. J. VAN DER AAR, G. C. Fahey Jr, and L. L. Berger. 1982. Influence of dietary fibers on performance and fermentation characteristics of gut contents from growing chicks. Poult. Sci. 61:1335-1343.

Salvin, J. L., N. L. Nelson, E. A. McNamara and K. Cashmere. 1985. Bowel function of healthy men consuming liquid diets with and without dietary fiber. J. Parenter. Entral. Nutr. 9:317321.

Samanya, M. and K. Yamauch. 2002. Histological alterations of intestinal villi in chickens fed dried Bacillus subtilis var. natto. Comp. Biochem. Physiol. Part A Physiol. 133:95-104.

SAS, 1998. SAS User's guide: Statistics, Version 7.0 ed. SAS Inst. Inc., Cary, NC, USA.

Sayrafi, R., R. Shahrooz, F. Soltanalinejad and S. Rahimi. 2011. Histomorphometrical study of the prebiotic effects on intestine morphology and growth performance of broiler chickens. V. R. F. 2:45-51.

Sen, S., H. P. S. Makkar and K. Becke. 1998. Alfalfa saponins and their implications in animal nutrition. J. Agric. Food Chem. 46:131-140.
Sibbald, I. R. 1979. Passage of feed through the adult rooster. Poult. Sci. 58:446-459.

Tivey, D. R. and M. W. Smith. 1989. Cytochemical analysis of single villus peptidase activities in pig intestine during neonatal development. Histochem. J. 21:601-608.

Yasar, S. and J. M. Forbes. 1999. Performance and gastrointestinal response of broiler chickens fed on cereal grainbased foods soaked in water. Br. Poult. Sci. 40:65-76.

Yason, C. V., B. A. Summers and K. A. Schat. 1987. Pathogenesis of rotavirus infection in various age groups of chickens and turkeys: Pathology. Am. J. Vet. Res. 6:927-938.

Yu, B., C. C. Tsai, J. C. Hsu and P. W. Chiou. 1998. Effect of different sources of dietary fibre on growth performance, intestinal morphology and caecal carbohydrates of domestic geese. Br. Poult. Sci. 39:560-567.

Zhang, A. W., B. D. Lee, S. K. Lee, K. W. Lee, G. H. An, K. B. Song and C. H. Lee. 2005. Effects of yeast (saccharomyces cerevisiae) cell components on growth performance, meat quality, and ileal mucosa development of broiler chicks. Poult. Sci. 84:1015-1021. 